\title{
Transoral robotic submandibular sialadenectomy: how and when
}

\author{
Pasquale Capaccio ${ }^{1,2}$, Filippo Montevecchi ${ }^{3}$, Giuseppe Meccariello ${ }^{3}$, Giovanni Cammaroto ${ }^{3}$, \\ Jeffery Scott Magnuson ${ }^{4}$, Stefano Pelucchi ${ }^{5}$, Lorenzo Bresciani ${ }^{1}$, Claudio Vicini ${ }^{3,5}$ \\ ${ }^{1}$ Department of Otolaryngology and Head and Neck Surgery, Fondazione IRCCS Ca' Granda Ospedale Maggiore Policlinico, Milan, Italy; \\ ${ }^{2}$ Department of Biomedical, Surgical and Dental Sciences, University of Milan, Milan, Italy; ${ }^{3}$ Head and Neck Department, ENT \& Oral Surgery \\ Unit, G.B. Morgagni-L. Pierantoni Hospital of Forlì, Forlì, Italy; ${ }^{4}$ Florida Hospital, Celebration, FL, USA; ${ }^{5}$ Otolaryngology Head and Neck \\ Surgery, University Hospital of Ferrara, Ferrara, Italy \\ Correspondence to: Pasquale Capaccio, MD. Department of Biomedical, Surgical and Dental Sciences, Fondazione IRCCS Ca' Granda Ospedale \\ Maggiore Policlinico, Mangiagalli e Regina Elena, University of Milan, Via F. Sforza 35, 20122 Milano, Italy. Email: pasquale.capaccio@unimi.it.
}

\begin{abstract}
Traditional removal of the submandibular gland is done through a transcervical approach; new proposals have come into the scientific limelight such as endoscopy-assisted transcervical sialadenectomy or (robot-assisted) submandibular sialadenectomy through a postauricular facelift transcervical approach. Transoral submandibular sialadenectomy has been described in the past, but with the advent of transoral robotic surgery, the proposal of removing the submandibular gland from the oral floor is gaining strength. A transoral robotic submandibular sialadenectomy by the Si Da Vinci Surgical Robot was performed in a 68-years-old female patient under general anaesthesia. The transoral robotic procedure was successful with no major postoperative complications. A mild tingling of the tip of the tongue was described by the patient 3 months after. The surgical time took 110 minutes. No residual gland was observed at ultrasonography. The transoral robotic submandibular sialadenectomy seems to be, with selective indication based on clinical and radiological assessment, a viable and safe alternative to traditional management in patients who refuse a cervical scar and the risk of paralysis of the facial nerve.
\end{abstract}

Keywords: Submandibular sialadenectomy; submandibular stones; transoral surgery; transoral robotic surgery (TORS)

Submitted Jan 05, 2020. Accepted for publication Feb 04, 2020.

doi: 10.21037 /gs.2020.02.04

View this article at: http://dx.doi.org/10.21037/gs.2020.02.04

\section{Introduction}

Traditional surgical management of the submandibular gland is based on the transcervical approach with known complications such as nerve injuries, unaesthetic scars, inflammatory residual glands, or duct stones with remnant inflammatory ducts (1-3). The development of conservative salivary techniques such as sialendoscopy (4-6) and sialendoscopy-assisted surgical transoral procedures (7-9) have provided a minimally invasive way of curing residual obstructing symptoms as a consequence of transcervical sialadenectomy (10). The risk of a residual unaesthetic scar has been partially solved by the so-called modified facelift or retroauricular approach; robotic surgery via modified facelift or the retroauricular route has been recently proposed for the transcervical removal of the submandibular gland (11-14). Following the transoral pathway, the risk of facial nerve injury is reduced. The transoral removal of the submandibular gland was proposed by Downtown and Quist in 1960 (15), but abandoned until the 2000s when it was newly proposed by means of traditional surgical approach (16-18), of an endoscopically-assisted surgical approach (19), and, more recently, by means of robot-assisted glandular surgery (20-22). Terris et al. (23) described the endorobotic resection of the submandibular gland in a cadaveric model through a transcervical approach in 2005. Only two case reports dealing with transoral robotic submandibular sialadenectomy (TORSS) have been described $(20,22)$. In 2003, we began our experience with sialendoscopy-assisted transoral surgery for the removal of hiloparenchymal 


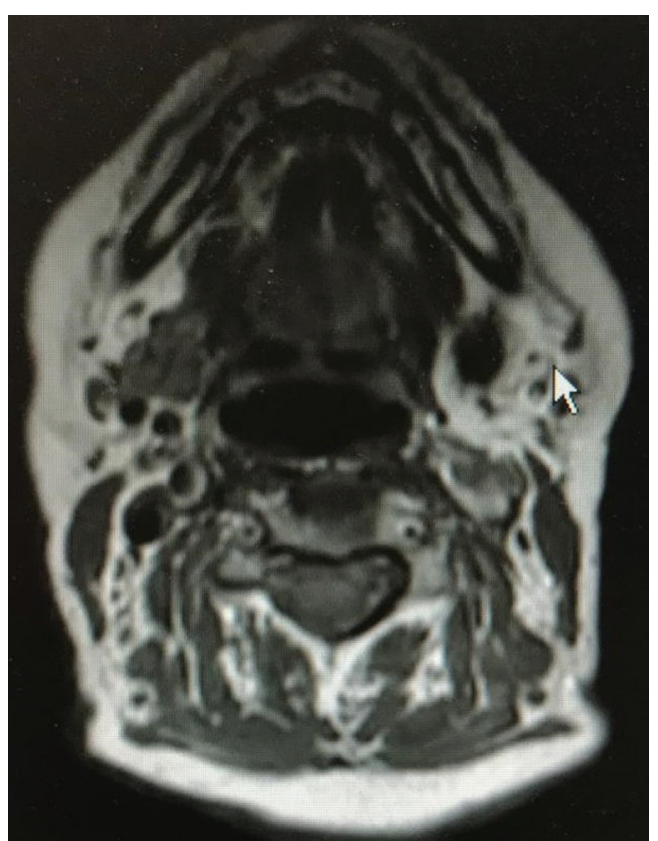

Figure $1 \mathrm{MR}$ image of the left submandibular gland with an intraparenchymal $1-\mathrm{cm}$ stone (white arrow indicating the gland). MR, magnetic resonance.

stones that nowadays represents the preferred alternative to transcervical submandibular sialadenectomy (24); we showed that up to $90 \%$ of these stones could be effectively removed through a conservative transoral approach $(8,9)$.

Residual indications for the removal of the submandibular gland are pure intraparenchymal stones, multiple parenchymal stones with a history of recurrent gland infections, iatrogenic proximal duct stenosis, and neoplasms (25). By matching our long-term experience with transoral robotic surgery (TORS) for oropharyngeal and salivary gland disorders (26-28), we present the TORSS by describing the robot docking, the surgical technique, the post-operative results, and indications for this new option.

\section{Subject and methods}

In April 2019, a female patient (68 years old) with recurrent infections of the left submandibular gland due to a pure intraparenchymal stone $(10 \mathrm{~mm})$ underwent a TORSS with Si Da Vinci surgical robot at the Head and Neck Department, ENT \& Oral Surgery Unit of the G.B. Morgagni-L. Pierantoni Hospital in Forlì, Italy. The patient underwent pre-operative ultrasound (US) and Doppler US assessments (Hitachi H21, 7.5 MHz, Hitachi High
Technology Corporation Ltd., Tokyo, Japan) and magnetic resonance imaging (MRI) (Figure 1) to reveal the location of the stone, the inflammatory condition of the gland, and the anatomical relationship of the gland and surrounding tissues as well as a clinical evaluation to establish the size of the stone and its location, which was clinically defined as a pure unpalpable parenchymal stone as no stone was detectable during bimanual palpation of the oral floor (8); the clinical evaluation verified that the gland easily moved upward to the oral floor by manual finger pressure of the neck. The exclusion criteria were an inability to open the mouth sufficiently $(8,9)$. Informed consent on the possible combination of a robotic transoral and traditional transcervical approach in the case of failure during the transoral approach was signed by the patient.

The study was approved by the appropriate local Ethical Committee CEILAV (Comitato Etico IRST IRCCS AVR Meldola) according to the principles stated in the Declaration of Helsinki and the patients gave informed consent for the study.

\section{Surgical procedure}

The procedure was performed under general anesthesia with a nasotracheal tube to maximize tongue exposure. The Molt mouth gag was introduced.

The Si Da Vinci surgical robot (Intuitive Surgical, Sunnyvale, CA, USA) was docked behind the head of the patient at an angle of $30^{\circ}$ (Figure 2) to obtain visualization of the surgical field by orientating it on the contralateral side of the gland. An $8.5-\mathrm{mm} 30^{\circ}$ downward-facing endoscope was placed into the scope holder. Two robotic 5-mm instruments, the Maryland dissector and monopolar cautery with spatula tip, were placed into arms 1 and 3.

A squarish tongue retractor, covered by a rough gauze, was positioned to retract the tongue to the contralateral side.

The robotic surgeon broke scrub and sat at the surgical console. The assistant surgeon was positioned at the contralateral side of the surgical field and used suction and a tongue retractor to flatten the oral floor. The duct was cannulated using a salivary probe (Bowman probes, Karl Storz, Tuttlingen, Germany). Using the monopolar cautery of the robot set at $15 \mathrm{~W}$ of coagulation, an oblique mucosal incision was made over the marked area near the papillar region of Wharton's duct, along the floor of the mouth toward the second molar. A blunt dissection of the loose areolar tissue was performed medially to the internal edge of the sublingual gland, which was rotated laterally to 


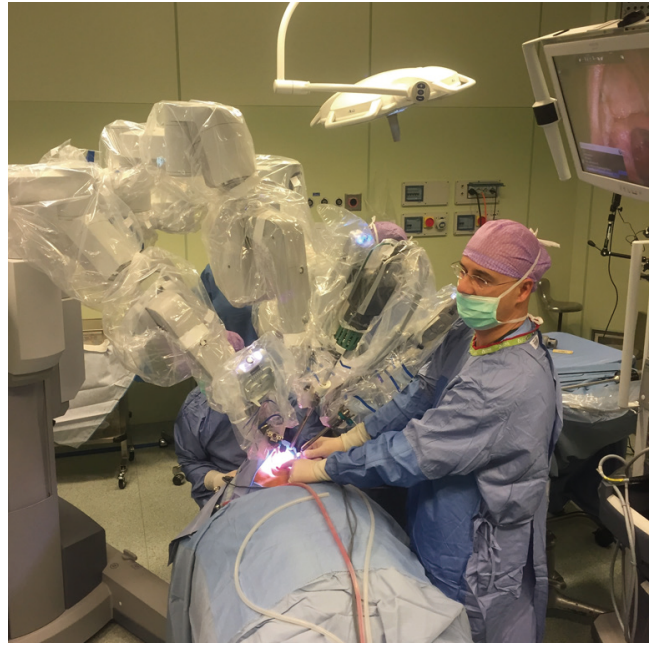

Figure 2 Docking of the Si Da Vinci Robot positioned behind the head of the patient on the opposite side of the affected gland with an angle of $30^{\circ}$.

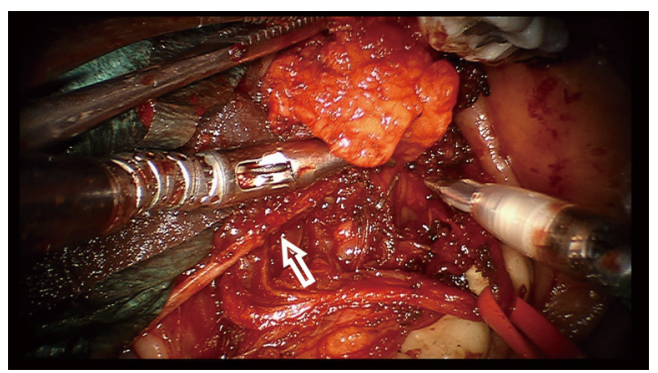

Figure 3 The entire gland with Wharton's duct removed from the oral floor before duct ligation (the white arrow indicates the Wharton's duct and the red neckbend is positioned around the lingual nerve).

expose Wharton's duct; the Wharton's duct was completely isolated and held with a colored neckbend (Figure 3). The horseshoe-shaped lingual nerve was easily identified running obliquely from the tongue, passing under the duct, and then ascending medially through the tail of the sublingual gland over Wharton's duct. The lingual nerve was mobilized from the duct and retracted medially to visualize the gland hilum, which was moved upward to the submandibular gland area by means of external finger pressure by the assistant surgeon. A colored neckbend was then positioned around the lateral tract of the lingual nerve near the mandibular body (Figure 3). A gentle incision with monopolar cautery combined with blunt dissection was done over a very thin muscular bandage corresponding to the mylohyoid muscle

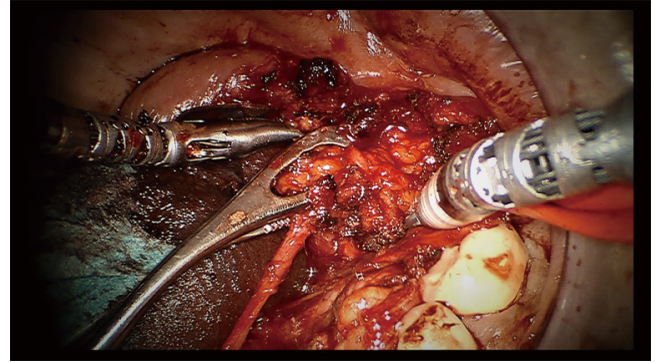

Figure 4 Tracking of the submandibular gland during robotic surgery.

to deliver the gland from the muscle. Gentle traction of the parenchyma of the submandibular gland was done by the assistant surgeon with a clamp instrument corresponding to the hilum (Figure 4). The facial artery was not encountered while the hypoglossal nerve was identified in the deep and posterior aspect of the submandibular gland. The submandibular gland was completely isolated and removed together with the proximal third of Wharton's duct (Figure 3). Hemostasis was done and a hemostatic surgical net was positioned to cover the surgical field. The docking was removed and surgery continued through a traditional transoral approach by suturing the oral floor with resorbable stitches (3.0 Vicryl).

The patient received antibiotic therapy (amoxicillin and clavulanic acid) for 1 week after the operation.

\section{Post-operative follow-up}

The patient was re-examined after 1 week, 1, 3 and 6 months to evaluate wound healing and any early or late post-operative complications. The patient underwent ultrasonography 3 months after the procedure to check for any residual parenchymal tissue.

\section{Results}

Prior to surgery, the US revealed a 10 -mm stone located in the parenchyma of the left submandibular gland. A US sclerotic pattern was observed with no clear signs of acute inflammation or adherence to the surrounding structures and an MRI confirmed the presence of the stone (Figure 2) and clearly depicted the relationship of the parenchyma with the surrounding anatomical structures with no signs of inflammation.

The left submandibular gland was successfully removed 
through the transoral approach by means of TORS (Video 1); no immediate untoward effects were encountered. The total surgical time was $110 \mathrm{~min}$ with $100 \mathrm{~min}$ of robotic time (including the docking time). The patient was discharged on post-op day 2. In the post-operative period, the patient referred lingual hypoesthesia and partial hypoglossal nerve deficit. Both symptoms resolved within 3 months after the surgical procedure except for a persisting tingling of the tip of the tongue. A soft diet was offered to the patient for the following 2 weeks and the patient returned to a normal diet after that period, notwithstanding the partial hypoglossal nerve deficit. At the 3 months postoperative US evaluation, no residual gland was observed.

\section{Discussion}

The application of robotic technology in the head and neck field $(26,27,29,30)$ has favored the spread of this procedure not only for oropharyngeal $(29,30)$ and, more recently, laryngeal (31) and neck disorders (32), but also for anterior oral floor diseases $(28,33)$. A transoral robotassisted management of large submandibular gland stones was recently described in a small and heterogeneous series of patients $(21,28,34,35)$, while only two case reports on TORSS have been published for different salivary disorders $(20,22)$. We report our step-by-step initial experience on TORSS and discuss the indications and robotic alternatives to traditional transcervical and transoral removal of the submandibular gland.

The submandibular gland was successfully removed through a transoral robotic approach into the floor of the mouth sparing nerves, sublingual gland, and without massive intraoperative and post-operative bleedings. Prosser et al. (20) excised the sublingual gland with TORS to favor the removal of the submandibular gland with recurrent sialadenitis. We described our initial experience on the removal of hiloparenchymal submandibular stones by TORS instead of a transcervical approach and stated that the submandibular gland parenchyma can be easily approached without removing the sublingual gland (28). In this regard, the ligation of Wharton's duct at the proximal third permitted maintaining the salivary drainage of sublingual gland. No immediate and late complications were observed. However, transient lingual hypoesthesia and limitation of tongue movements with a complete recovery within 3 months was seen, except for tingling of the tip of the tongue. These complications are observed after traditional transoral removal of the submandibular gland (17); this finding can be partly explained by the possible crush trauma to the lingual muscles and lingual nerve during the detachment of the submandibular gland parenchyma. Furthermore, the transoral approach has a narrow surgical field; consequently, the risk of injury to the surrounding structures is quite high. These limitations were overcome by the magnified three-dimensional view given by the robotic scope that permits the main surgeon to have a clear anatomical delineation and enhanced depth perception of the floor of the mouth, lingual nerve and Wharton's duct, the sublingual and submandibular gland, and the hypoglossal nerve.

Another crucial anatomical point is the facial artery. Authors have simply described the coagulation of branches of the facial artery (36), others (22) have converted the robotic procedure to traditional transoral surgery to clamp and ligate the facial artery, and some have not found the facial artery during robotic surgery. Accordingly, we did not find the main trunk of the facial artery but simply coagulated small vessels in the posterior part of the gland. Our initial experience is concordant with that of other authors (20), who have assured of the minimal risks of the involvement of the facial vessel package during TORS. The robot-assisted excision of the submandibular gland through a postauricular facelift approach has become a viable option to cure benign salivary disorders (including benign neoplasms) with better cosmetic outcomes (11-14) as well as for the TORS for the removal of the submandibular gland $(20,22)$. There is no mention in the literature about the postoperative occurrence of any case of facial nerve deficit, and in this regard, the facelift procedure can be considered safe with a very low risk of complications (facelift). Further experience with the transoral robotic approach is necessary to confirm the safety of this procedure as has been observed for the facelift approach. We observed that blunt dissection with the spatula supported by the delicate grip of the Maryland forceps guaranteed a clear and bloodless surgical field, thus achieving a better view of the deep surgical plane, also facilitated by an adequate docking of the robot $(26,27)$. The robotic scopes and arms should be positioned behind the head of the patient and on the opposite side with respect to the involved gland at an angle of $30^{\circ}$; moreover, a better view of the posterior part of the oral floor can be realized with a $30^{\circ}$ downwardfacing endoscope. Unless used for the transoral robotic removal of parenchymal submandibular stones where the presence of the main surgeon and one assistant surgeon is sufficient (the assistant surgeon can simultaneously 
suction the oral field and push up the submandibular gland from the neck to better expose the parenchyma), the TORSS can be performed with the help of an assistant (useful for gland pushing up) as the second surgeon is involved in the suction and tracking of the parenchyma of the gland from the oral floor. Finally, the robotic surgical time was shorter than previously reported (22) (100 minutes for the robotic procedure including docking). In our opinion, by increasing the number of robotic procedures, the surgical time will be further reduced according to the robotic learning curves (37).

\section{Conclusions}

TORSS seems to be a viable and safe alternative surgical technique to the traditional transcervical (endoscopyassisted or not) submandibular sialadenectomy or the more recent robot-assisted postauricular facelift excision of the submandibular gland. This approach is aimed at patients who refuse a cutaneous scar (although aesthetic) and the risk of facial nerve paralysis. Thanks to the three dimensional and enhanced depth perception of the oral floor, the robotic approach allows the anatomical course of the lingual nerve and the hypoglossal nerve to be followed, and for the submandibular duct to remain healthy until the removal of the gland with its ligation at the proximal third, thus preserving the function of the sublingual gland. An adequate clinical (the gland has to be easily moved up toward the oral floor with no adherence) and radiological (no signs of inflammation or adherence visible in the US and MRI images) evaluation is mandatory to identify patients suitable for the transoral procedure. Based on our longterm experience of robotic surgery and the management of salivary disorders, ideal candidates would have a mobile submandibular gland and symptomatic unpalpable single or multiple parenchymal stones, a chronic or recurrent inflammation of the gland with a sclerotic or atrophic pattern and clear margins in the US and MRI, and small benign neoplasms with adequate healthy tissue from the superficial layer of the gland (22).

\section{Acknowledgments}

Funding: None.

\section{Footnote}

Conflicts of Interest: All authors have completed the ICMJE uniform disclosure form (available at http://dx.doi. org/10.21037/gs.2020.02.04). The authors have no conflicts of interest to declare.

Ethical Statement: The authors are accountable for all aspects of the work in ensuring that questions related to the accuracy or integrity of any part of the work are appropriately investigated and resolved. The study was approved by the appropriate local Ethical Committee CEILAV (Comitato Etico IRST IRCCS AVR Meldola) according to the principles stated in the Declaration of Helsinki and the patients gave informed consent for the study.

Open Access Statement: This is an Open Access article distributed in accordance with the Creative Commons Attribution-NonCommercial-NoDerivs 4.0 International License (CC BY-NC-ND 4.0), which permits the noncommercial replication and distribution of the article with the strict proviso that no changes or edits are made and the original work is properly cited (including links to both the formal publication through the relevant DOI and the license). See: https://creativecommons.org/licenses/by-nc-nd/4.0/.

\section{References}

1. Hald J, Andreassen UK. Submandibular gland excision: short- and long-term complications. ORL J Otorhinolaryngol Relat Spec 1994;56:87-91.

2. Papaspyrou G, Werner JA, Sesterhenn AM. Transcervical extirpation of the submandibular gland: the University of Marburg experience. Eur Arch Otorhinolaryngol 2014;271:2009-12.

3. Milton CM, Thomas BM, Bickerton RC. Morbidity study of submandibular gland excision. Ann R Coll Surg Engl 1986;68:148-50.

4. Nahlieli O, Baruchin AM. Long-term experience with endoscopic diagnosis and treatment of salivary gland inflammatory diseases. Laryngoscope 2000;110:988-93.

5. Capaccio P, Torretta S, Ottaviani F, et al. Modern management of obstructive salivary diseases. Acta Otorhinolaryngol Ital 2007;27:161-72.

6. Zenk J, Koch M, Klintworth N, et al. Sialendoscopy in the diagnosis and treatment of sialolithiasis: a study on more than 1000 patients. Otolaryngol Head Neck Surg 2012;147:858-63.

7. Marchal F. Combined endoscopic and external approach for extraction of large stones with preservation of parotid 
and submandibular glands. Laryngoscope 2007;117:373-7.

8. Capaccio P, Clemente IA, McGurk M, et al. Transoral removal of hiloparenchymal submandibular calculi: a long-term clinical experience. Eur Arch Otorhinolaryngol 2011;268:1081-6.

9. Capaccio P, Gaffuri M, Rossi V, et al. Sialendoscopeassisted transoral removal of hilo-parenchymal submandibular stones: surgical results and subjective scores. Acta Otorhinolaryngol Ital 2017;37:122-7.

10. Sequeira SM, Nussenbaum B, Ogden MA. Interventional sialendoscopy after sialadenectomy. Laryngoscope 2013;123:1204-6.

11. De Virgilio A, Park YM, Kim WS, et al. Robotic sialadenectomy of the submandibular gland via modified face-lift approach. Int J Oral Maxillofac Surg 2012;41:1325-9.

12. Lee HS, Park DY, Hwang CS, et al. Feasibility of robot-assisted submandibular gland resection via retroauricular approach: preliminary results. Laryngoscope 2013;123:369-73.

13. Yang TL, Li H, Holsinger FC, et al. Submandibular gland resection via the trans-hairline approach: a preclinical study of a novel flexible single-port surgical system and the surgical experiences of standard multiarm robotic surgical systems. Head Neck 2019;41:2231-8.

14. Singh RP, Sung ES, Song CM, et al. Robot-assisted excision of the submandibular gland by a postauricular facelift approach: comparison with the conventional transcervical approach. Br J Oral Maxillofac Surg 2017;55:1030-4,

15. Downtown D, Quist G. Intra-oral excision of the submandibular gland. Proc R Soc Med 1960;53:543-4.

16. Smith AD, Elahi MM, Kawamoto HK Jr, et al. Excision of the submandibular gland by an intraoral approach. Plast Reconstr Surg 2000;105:2092-5.

17. Hong KH, Yang YS. Surgical results of the intraoral removal of the submandibular gland. Otolaryngol Head Neck Surg 2008;139:530-4.

18. Kauffman RM, Netterville JL, Burkey BB. Trans-oral excision of the submandibular gland: techniques and results of nine cases. Laryngoscope 2009;119:502-7.

19. Guerrissi JO, Taborda G. Endoscopic excision of the submandibular gland by an intraoral approach. J Craniofac Surg 2001;12:299-303.

20. Prosser JD, Bush CM, Solares CA, et al. Trans-oral robotic submandibular gland removal. J Robot Surg 2013;7:87-90.

21. Marzouk MF. Robot-assisted glandular surgery. Atlas Oral Maxillofac Surg Clin North Am 2018;26:153-7.
22. Lin X, Liang L, Shao X, et al. Trans-oral robotic surgery of submandibular gland removal with preservation of sublingual gland and Wharton's duct. J Craniofac Surg 2019;30:237-8.

23. Terris DJ, Haus BM, Gourin CG, et al. Endo-robotic resection of the submandibular gland in a cadaveric model. Head Neck 2005;27:946-51.

24. Capaccio P, Bottero A, Pompilio M, et al. Conservative transoral removal of hilar submandibular salivary calculi. Laryngoscope 2005;115:750-2.

25. Capaccio P, Torretta S, Pignataro L. The role of adenectomy for salivary gland obstructions in the era of sialoendoscopy and lithotripsy. Otolaryngol Clin North Am 2009;42:1161-71.

26. Cammaroto G, Montevecchi F, D'Agostino G, et al. Palatal surgery in a transoral robotic setting (TORS): preliminary results of a retrospective comparison between uvulopalatopharyngoplasty (UPPP), expansion sphincter pharyngoplasty (ESP) and barbed repositioning pharyngoplasty (BRP). Acta Otorhinolaryngol Ital 2017;37:406-9.

27. Montevecchi F, Caranti A, Cammaroto G, et al. Transoral Robotic Surgery (TORS) for Bilateral Eagle Syndrome. ORL J Otorhinolaryngol Relat Spec 2019;81:36-40.

28. Capaccio P, Montevecchi F, Meccariello G, et al. Transoral robotic surgery for hilo-parenchymal submandibular stones: step-by-step description and reasoned approach. Int J Oral Maxillofac Surg 2019;48:1520-4.

29. Weinstein GS, O’Malley BW Jr, Cohen MA, et al. Transoral robotic surgery for advanced oropharyngeal carcinoma. Arch. Otolaryngol. Head Neck Surg 2010;136:1079-85.

30. Nakayama M, Holsinger FC, Chevalier D, et al. The dawn of robotic surgery in otolaryngology: head and neck surgery. Jpn J Clin Oncol 2019;49:404-11.

31. Orosco RK, Tam K, Nakayama M, et al. Transoral supraglottic laryngectomy using a next-generation singleport robotic surgical system. Head Neck 2019;41:2143-7.

32. Rao V, Prasad R, Subash A, et al. Technique of flap elevation for robot assisted selective neck dissection via retroauricular approach: a surgeon's guide. J Robot Surg 2020;14:337-41.

33. Walvekar RR, Peters G, Hardy E, et al. Robotic-assisted transoral removal of a bilateral floor of mouth ranulas. World J Surg Oncol 2011;9:78.

34. Walvekar RR, Tyler PD, Tammareddi N, et al. Roboticassisted transoral removal of a submandibular megalith. Laryngoscope 2011;121:534-7. 
35. Razavi C, Pascheles C, Samara G, et al. Robot-assisted sialolithotomy with sialendoscopy for the management of large submandibular gland stones. Laryngoscope 2016;126:345-51.

36. Weber SM, Wax MK, Kim JH. Transoral excision of

Cite this article as: Capaccio P, Montevecchi F, Meccariello G, Cammaroto G, Magnuson JS, Pelucchi S, Bresciani L, Vicini C. Transoral robotic submandibular sialadenectomy: how and when. Gland Surg 2020;9(2):423-429. doi: 10.21037/gs.2020.02.04 the submandibular gland. Otolaryngol Head Neck Surg 2007;137:343-5.

37. Walliczek U, Förtsch A, Dworschak P, et al. Effect of training frequency on the learning curve on the da Vinci Skills Simulator. Head Neck 2016;38 Suppl 1:E1762-9. 